\title{
Wie viel wäre Ihre Hausarztpraxis bei einem Aufkauf wert?
}

- Warum geht man in Deutschland trotz steigender Arztzahlen und einer im internationalen Vergleich hohen Arztdichte von einem Ärztemangel aus? Das PROGNOS-Institut ging im Auftrag der Krankenkassen dieser Frage nach. Nach Auffassung des Instituts lässt sich dieser Umstand damit erklären, dass die niedergelassenen Ärztinnen und Ärzte regional sehr ungleich verteilt sind. Eine Möglichkeit, diese ungleiche Verteilung abzubauen, besteht darin, Praxen in überversorgten Gebieten aufzukaufen und nicht neu zu besetzen. $\$ 105$ Abs. 3 SGB V gestattet dies den KVen bereits heute.

Die Analyse führt zum Ergebnis, dass fast 7000 Ärztinnen und Ärzte in den nächsten

\section{Tabelle 1}

\begin{tabular}{l|c|}
\hline KV & Wert $€$ \\
\hline Baden-Württemberg & 86426 \\
\hline Bayern & 84475 \\
\hline Brandenburg & 97748 \\
\hline Berlin & 75073 \\
\hline Bremen & 87263 \\
\hline Hamburg & 86850 \\
\hline Hessen & 99331 \\
\hline $\begin{array}{l}\text { Mecklenburg- } \\
\text { Vorpommern }\end{array}$ & 98435 \\
\hline Niedersachsen & 107127 \\
\hline Nordrhein & 92003 \\
\hline Rheinland-Pfalz & 93576 \\
\hline Saarland & 97252 \\
\hline Sachsen & 92203 \\
\hline Sachsen-Anhalt & 100571 \\
\hline Schleswig-Holstein & 86892 \\
\hline Thüringen & 96149 \\
\hline $\begin{array}{l}\text { Westfalen-Lippe } \\
\text { Zu diesem Preis könnte eine haus- } \\
\text { ärtliche Praxis aufgekauft oder } \\
\text { Bemerkauft werden (Quelle: PROGNOS). } \\
\text { eingeschätzten Werte in den Neuen } \\
\text { Bundesländern! }\end{array}$ & 94080 \\
\hline
\end{tabular}

fünf Jahren in den Ruhestand gehen könnten, ohne dass der Versorgungsgrad in einer Region unter $130 \%$ sinkt. Da ein Planungsbereich ab einem Versorgungsgrad von $110 \%$ als überversorgt gilt, könnten nach Auffassung des Instituts sogar nahezu 12000 Ärzte aus der vertragsärztlichen Versorgung ausscheiden, ohne dass ein Engpass entsteht. In den von Unterversorgung bedrohten Gebieten könnte dann parallel die Versorgungslage verbessert werden, wenn es gelänge, Neuniederlassungen hier anzusiedeln.

Bei Hausärzten sieht das Institut dabei allerdings nur einen geringen Spielraum für den Aufkauf von Arztpraxen: Mit Ausnahme des Landkreises Starnberg und der Stadtkreise München und Freiburg weisen alle Planungsbereiche einen Versorgungsgrad von unter $130 \%$ auf. Bundesweit wird der Versorgungsgrad von $130 \%$ sogar nur mit lediglich 32 Hausärzten überschritten, bezogen auf die relative Überversorgung von $110 \%$ würde sich diese Zahl lediglich auf 765 Hausärzte erhöhen. Das entspricht bei bundesweit 53019 niedergelassenen Hausärzten einer relativen Überversorgung von rund $1,4 \%$.

\section{MMW Kommentar}

Das Gutachten wurde in weiten Kreisen der Ärzteschaft mit großer Empörung aufgenommen, obgleich das hier zugrunde gelegte Datenmaterial nur bekräftigt, was längst bekannt ist: Im fachärztlichen Bereich gibt es nur bei Augenärzten, HNO-Ärzten und Gynäkologen einen drohenden Ärztemangel. Bei Hausärzten bewegen sich die Zahlen schon jetzt an der Grenze der Belastbarkeit und angesichts der hohen Überalterung - 28,5\% der deutschen Hausärzte waren 2010 in einem Alter von 60 oder darüber - wird sich die Situation zunehmend verschlimmern. Interessant sind aber auch die Erhebungen von PROGNOS im Hinblick auf die Bewertung von Praxen, die aufgekauft werden könnten (siehe Tabelle). Hier ergeben sich nach Angaben von PROGNOS, bezogen auf den ideellen und den Substanzwert, Summen zwischen rund 75000 und rund 130000 Euro, je nach Region. Die Werte können dabei durchaus zur Orientierung bei einem geplanten Praxisverkauf herangezogen werden, vorausgesetzt natürlich, man findet als Hausarzt einen Praxisnachfolger.

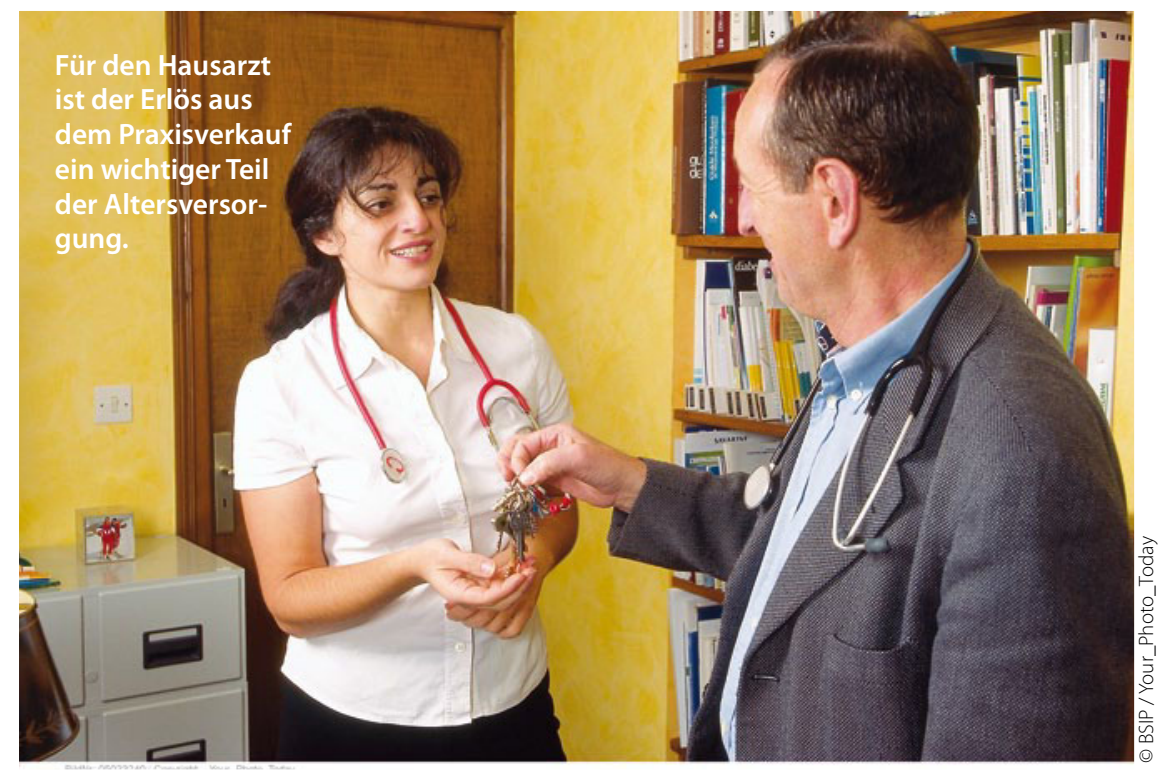

